\title{
COMPLICATIONS OF STATIN THERAPY AND THEIR MANAGEMENT
}

\author{
Biswajit Das ${ }^{1}$, Trinath Kumar Mishra ${ }^{2}$
}

${ }^{1}$ Associate Professor, Department of Cardiology, SCB Medical College, Cuttack, Odisha.

2Professor, Department of Cardiology, MKCG Medical College, Berhampur, Odisha.

\section{ABSTRACT}

Several large scale trials have conclusively proved the ability of statin to reduce risk of vascular death, nonfatal myocardial infarction and stroke. At the same time, use of statins has been shown to produce adverse effects like myopathy, rhabdomyolysis and increased incidence of diabetes mellitus, besides its effect on liver enzymes. Rhabdomyolysis, a rare side effect of statin can cause acute renal failure and death. The underlying cause of statin induced myopathy remains unclear. Interruption of ubiquinone synthesis is one hypothesis. High dose of statin can induce myopathy. Other rare effects of statin therapy include impairment of cognitive function and peripheral neuropathy. The present article reviews adverse effects of statin therapy and the mechanisms responsible.

\section{KEYWORDS}

Statin, Myopathy, Coq10.

HOW TO CITE THIS ARTICLE: Das B, Mishra TK. Complications of statin therapy and their management. J. Evolution Med. Dent. Sci. 2016;5(66):4745-4750, DOI: 10.14260/jemds/2016/1081

\section{INTRODUCTION}

Several pathological, epidemiological, genetic and interventional trials have validated the central tenet of the cholesterol hypothesis, which proposes a causal relationship between hypercholesterolemia and atherogenesis and identifies the lipid modification as a risk-reducing strategy for Coronary Artery Disease (CAD). Surprisingly, doubts lingered regarding the role of cholesterol in atherosclerosis until recently. Again, despite the evidence that high serum cholesterol levels correlated with coronary deaths, the proposition that cholesterol lowering therapy could reduce CAD morbidity remained largely unproven. In fact, some cholesterol-lowering medications appeared to cause an increase in the incidence of some events including noncoronary deaths. Dietary interventions to lower cholesterol often proved ineffective and such results seemed to challenge the validity of cholesterol as a therapeutic target.

Conclusive evidence regarding cholesterol hypothesis awaited clinical trials of cholesterol lowering using the statins, agents that lowered low-density lipoprotein cholesterol (LDLC) much more efficiently than previously available drugs like bile acid binding resins. Statins are a widely used group of cholesterol lowering agents that act by inhibiting the enzyme 3-hydroxy 3-methylglutaryl CoA (HMG CoA) reductase, which catalyses the rate-limiting step in cholesterol biosynthesis. ${ }^{1}$ Since statins were first approved in 1987, their ability to reduce the risks of vascular death, non-fatal myocardial infarction, stroke and the need for arterial revascularization procedures has been shown by several large, high-quality randomized trials. ${ }^{2}$ Simultaneous with the quantum leap in the use of statins, concern was raised regarding the adverse effects of statin therapy.

Financial or Other, Competing Interest: None.

Submission 05-03-2016, Peer Review 17-04-2016,

Acceptance 23-04-2016, Published 18-08-2016.

Corresponding Author:

Dr. Trinath Kumar Mishra,

Professor and HOD,

Department of Cardiology,

Bhabhonagar, $2^{\text {nd }}$ Lane,

Berhampur-760004,

Odisha.

E-mail:drtkmishra@yahoo.com

DOI: 10.14260/jemds/2016/1081
This article reviews the incidence and characteristics of adverse effects of statins and their management.

\section{Statins: Metabolism and Adverse Effects}

Currently, seven statins are available in most parts of the world: lovastatin, simvastatin, pravastatin, fluvastatin, atorvastatin, rosuvastatin and pitavastatin. In India, simvastatin and atorvastatin are the most commonly used statins. Statins are metabolized in the liver. Lovastatin, simvastatin, atorvastatin and fluvastatin are metabolized by cytochrome P450 3A4 and 2C9 systems, whereas rosuvastatin and pitavastatin are minimally metabolized by these enzyme systems (Table 1).

Pravastatin is metabolized by sulphation and subsequent biliary and urinary excretion. Hence, any concomitant use of drugs that inhibit the cytochrome P-450 system can increase plasma concentration of statins. ${ }^{3}$ These include macrolide antibiotics (Erythromycin, clarithromycin), azole antifungals (Ketoconazole, miconazole) and anti-arrhythmic agents (Amiodarone, verapamil). Statins also vary in their propensity to cause drug interactions through other mechanisms (e.g. by blocking organic anion transporter peptides). ${ }^{4}$ Genetic polymorphisms within these systems also affect drugs disposition and the likelihood of interaction.

Certain well-documented, consistent adverse effects associated with statin are muscle toxicity including myopathy and rhabdomyolysis and effects on liver enzymes. ${ }^{1}$ Many other possible side effects are listed in the product information, but given the lack of confirmatory evidence form large controlled randomized trials; these are likely to be either rare or not truly caused by the statin treatment. 5

\section{Effects on Muscle}

All statins can cause myopathy and rhabdomyolysis. ${ }^{6}$ Myopathy is defined as any muscle symptom - pain, tenderness or weakness, accompanied by a creatine kinase concentration greater than ten times the upper limit of normal for the particular laboratory. ${ }^{7}$ Rhabdomyolysis is severe myopathy involving muscle breakdown and myoglobin release into the circulation, which can cause a brown discolouration of urine and risk of renal failure. Rhabdomyolysis is diagnosed when creatine kinase concentration is greater than 40 times the 
upper limit of normal or there is evidence of end organ damage (e.g. acute renal failure or worsened renal function) or both. ${ }^{5}$ Myalgia refers to muscle pain with no rise in creatine kinase concentration to greater than ten times the upper limit of normal. ${ }^{5}$

\begin{tabular}{|c|c|c|c|}
\hline & $\begin{array}{c}\text { Licensed } \\
\text { Dose Range } \\
\text { (\% LDL } \\
\text { Cholesterol } \\
\text { Reduction) }\end{array}$ & Metabolism & $\begin{array}{c}\text { Most } \\
\text { Important } \\
\text { Drug } \\
\text { Interactions } \\
\text { Increasing } \\
\text { Myopathy } \\
\text { Risk }^{* *} \\
\end{array}$ \\
\hline Lovastatin & $\begin{array}{c}20-80 \mathrm{mg} \\
\text { daily (30\% } \\
\text { with } 40 \mathrm{mg} \text { ) }\end{array}$ & $\begin{array}{l}\text { Mainly } \\
\text { CYP3A4 }\end{array}$ & $\begin{array}{c}\text { Potent } \\
\text { inhibitors of } \\
\text { CYP3A4*** }\end{array}$ \\
\hline Simvastatin & $\begin{array}{l}10-80 \mathrm{mg} \\
(41 \% \text { with } \\
40 \mathrm{mg}) \\
\end{array}$ & $\begin{array}{l}\text { Mainly } \\
\text { CYP3A4 }\end{array}$ & $\begin{array}{c}\text { Potent } \\
\text { inhibitors of } \\
\text { CYP3A4 }\end{array}$ \\
\hline Pravastatin & $\begin{array}{c}20-80 \mathrm{mg} \\
\text { daily (34\% } \\
\text { with } 40 \mathrm{mg} \text { ) }\end{array}$ & $\begin{array}{c}\text { Sulphation, } \\
\text { biliary and } \\
\text { urinary } \\
\text { excretion }\end{array}$ & \\
\hline Fluvastatin & $\begin{array}{c}40-80 \mathrm{mg} \\
\text { daily (23\% } \\
\text { with } 40 \mathrm{mg} \text { ) }\end{array}$ & $\begin{array}{c}\text { CYP2C9 (some } \\
\text { CYP2C8 and } \\
\text { CYP3A4) }\end{array}$ & $\begin{array}{l}\text { Inhibitors of } \\
\text { CYP2C9 }\end{array}$ \\
\hline Atorvastatin & $\begin{array}{c}10-80 \mathrm{mg} \\
\text { daily (38\% } \\
\text { with } 10 \mathrm{mg} \text { ) }\end{array}$ & CYP3A4 & $\begin{array}{c}\text { Potent } \\
\text { inhibitors of } \\
\text { CYP3A4 } \\
\end{array}$ \\
\hline Rosuvastatin & $\begin{array}{c}5-40 \mathrm{mg} \\
\text { daily (45\% } \\
\text { with } 10 \mathrm{mg})\end{array}$ & $\begin{array}{c}\text { Minimal } \\
\text { metabolism } \\
\text { (via CYP2CP } \\
\text { and some } \\
\text { CYP2C19) and } \\
\text { biliary } \\
\text { excretion }\end{array}$ & Unclear \\
\hline Pitavastatin & $\begin{array}{c}2-4 \mathrm{mg} \text { daily } \\
\text { (42\% with } 2 \\
\mathrm{mg})\end{array}$ & $\begin{array}{c}\text { Minimal } \\
\text { metabolism } \\
\text { (via CYP2C8 } \\
\text { and CYP2C9), } \\
\text { lactonization } \\
\text { and biliary } \\
\text { excretion }\end{array}$ & \\
\hline
\end{tabular}

LDL: Low-Density Lipoprotein

*Typically, doubling of a statin dose produces an additional $6 \%$ absolute decrease in LDL cholesterol - e.g. simvastatin $20 \mathrm{mg}$ daily reduces LDL by $35 \%$ and $40 \mathrm{mg}$ daily by $41 \%$.

**With all statins, the risk of myopathy is also increased by cyclosporine, gemfibrozil and possibly other fibrates.

***Including itraconazole, ketoconazole, erythromycin, clarithromycin, telithromycin, nefazodone, HIV protease inhibitors and regular ingestion of grapefruit juice.

\section{Mechanism}

The underlying cause of statin-associated myopathy is unclear. As already stated, statins work by inhibiting the formation of HMG-CoA reductase, which is essential in the production of mevalonate. Mevalonate is a component in the biosynthetic pathway that is shared by cholesterol, ubiquinone also known as coenzyme Q. sub.10 and isoprenylated regulatory proteins. One theory explaining the adverse effects on muscle involves the interruption in the synthesis of ubiquinone. ${ }^{5}$ Ubiquinone is involved in the energy production via the mitochondrial respiratory chain and a decrease in ubiquinone can explain some adverse muscle effects. Another theory suggests that the reduction of cholesterol in skeletal muscle makes the cell membrane unstable and vulnerable for destruction.

\section{Standard Doses of Statins and Effects on Muscle}

Standard dose refers to the commonly prescribed daily doses of statins, which typically reduce LDL cholesterol by $30-45 \%$ (i.e. atorvastatin $10-20 \mathrm{mg}$, fluvastatin $40-80 \mathrm{mg}$, simvastatin 20-40 $\mathrm{mg}$ and rosuvastatin $10 \mathrm{mg})^{5}$

For persons talking statins, the cohort study data indicate a very low incidence of rhabdomyolysis of 3.4 per 100,000 person years with a narrow $95 \%$ confidence interval (CI) of 1.6 - 6.5 per 100,000 person years. $^{6}$ A study from Japan, which enrolled 51,000 persons taking simvastatin with 175,000 person years of follow-up did not report a single case of rhabdomyolysis. ${ }^{7}$ However, the dose of simvastatin (5 $\mathrm{mg} /$ day) was lower than the generally used dose. The study suggests low risk at low dose. In the trials of simvastatin at doses of 20 to $40 \mathrm{mg} /$ day, the excess incidence of myopathy among those on simvastatin is $<0.01 \%$ per year. 8,9 A systematic review of randomized statin trials and cohort studies provides an overall estimated risk of myopathy with statin use of 11 per 100,000 person years of follow-up with the risk of rhabdomyolysis in about one-third of this (3-4 per 100,000 person years). ${ }^{10}$

\section{Higher Doses and Effects on Muscle}

Almost 25,000 patients have been randomized into trials comparing atorvastatin $80 \mathrm{mg} /$ day with various standard statin regimens or placebo. ${ }^{10-13}$ No excess risk of myopathy was reported among those allocated this dose of atorvastatin in these trials (Table 2). A doubling of the risk of myalgia leading to discontinuation of treatment was seen in one of these trials where atorvastatin $80 \mathrm{mg} /$ day was compared with simvastatin. ${ }^{11}$ However, the trial's open design makes interpretation of this finding difficult and no similar excess of treatment-related myalgia was seen in the masked comparison with atorvastatin $10 \mathrm{mg} /$ day $(4.8 \%$ atorvastatin $80 \mathrm{mg}$ vs $4.7 \% 10 \mathrm{mg} /$ day; $\mathrm{p}=0.72) .{ }^{10}$ or in the trial versus placebo (5.5\% atorvastatin $80 \mathrm{mg}$ vs $6 \%$ placebo). ${ }^{13}$ One trial has reported using simvastatin $80 \mathrm{mg} /$ day among 4497 participants with acute coronary syndromes. ${ }^{12}$ Patients were allocated either simvastatin $40 \mathrm{mg}$ daily for one month increasing to $80 \mathrm{mg}$ daily or to placebo for 4 months followed by simvastatin $20 \mathrm{mg}$ daily for 2.4 years. In this trial, there was higher myopathy risk with simvastatin $80 \mathrm{mg}$ daily with nine cases of myopathy among those allocated $80 \mathrm{mg}$ compared with only one in the standard treatment group who was on placebo at the time.

\section{Incidence of Rhabdomyolysis for Different Statins}

The incidence of rhabdomyolysis may be higher among persons taking lovastatin, simvastatin and atorvastatin (Because they are metabolized by cytochrome P450 3A4mediated oxidation, which is inhibited by several commonly used drugs), than fluvastatin (Oxidised by CYP2A9) or pravastatin (Not metabolized by CYP450 system). ${ }^{8}$ The notification rate of rhabdomyolysis to the US Food and Drug Administration Adverse Reporting System (FDAAERS) was about 4 times higher for monotherapy with lovastatin, simvastatin and atorvastatin (Mean rate, 0.73; 95\% CI, 0.64- 
0.82 per 1 million prescriptions [264 cases]) than for monotherapy with pravastatin and fluvastatin (Mean rate, 0.15 ; $95 \%$ CI, $0.09-0.24$ per 1 million prescriptions [ 18 cases]), $\mathrm{p}<0.001 .{ }^{14}$ The incidence of rhabdomyolysis in persons taking lovastatin, simvastatin and atorvastatin is about 4 per 100,000 person years; for fluvastatin and pravastatin it is about 4 times lower (Around 1 per 100,000 person years). ${ }^{15}$

This safety advantage does not mean, however, that fluvastatin and pravastatin should be the preferred statins, because they are less effective than simvastatin, lovastatin and atorvastatin at lowering blood cholesterol levels. ${ }^{16}$

\section{Is Myalgia Caused by the Statins}

Despite causing myopathy, there is no clear evidence from randomized trials that statins cause myalgia, although this is widely believed. ${ }^{5}$ In the large randomized controlled Heart Protection Study, 6-7\% of participants reported new or unexplained muscle pain or weakness at each time-point after randomization, but at no time were there any significant differences between those allocated active simvastatin compared with those on placebo. ${ }^{17}$ By the end of the study, $32.9 \%$ of those on simvastatin and $33.2 \%$ on placebo had reported muscle pain at least once. Similarly, reports of muscle cramp do not seem to increase with statin treatment. ${ }^{5}$ Asymptomatic elevation of creatine kinase can sometimes occur with statin therapy, but its clinical relevance is not clear. Thus, all statins occasionally cause myopathy which can progress to rhabdomyolysis. It is rare with the standard doses, but the risk increases with higher statin doses (Although with atorvastatin $80 \mathrm{mg} /$ day, the risk is very low). The risk of rhabdomyolysis is not clearly related to the LDL-lowering efficacy; for example, cerivastatin (Now withdrawn) was not particularly effective, but was much more likely than other statins to cause rhabdomyolysis. 16

Other lipid-lowering agents, in particular fibrates, also rarely cause myopathy. Combination of statins with gemfibrozil increases the risk of myopathy, because the latter increases plasma concentration of statins by inhibiting their glucuronidation. ${ }^{16}$ The risk of myopathy with all statins seems to be particularly affected by drug interactions that are sometimes related to metabolism of particular statins via the cytochrome P450 system (Table 1). The reasons for the greater toxicity of gemfibrozil than other fibrates remain poorly understood.

Identifiable risk factors for statin-induced myopathy are older age ( $>80$ years), sex (More in women than men), smaller body frame and fragility, multisystem disease (Including chronic renal insufficiency, especially among diabetics), the perioperative period, co-administration of certain medications and hypothyroidism.

\section{Detection of Muscle Involvement}

Routine measurement of creatine kinase is neither helpful nor cost effective for detecting rare cases of myopathy who are on standard doses of statin. Rather, the patients should be asked to report new or unexplained muscle pain or weakness. Creatine kinase should be measured in such patients only. As muscle pain is very common even without myopathy, other causes such as undue physical activity, trauma, thyroid disease and infections which can also raise creatine kinase should be considered first. Muscle weakness and bilateral proximal muscle weakness/pain are more specific symptoms of myopathy. ${ }^{5}$ Myopathy is present in such patients if creatine kinase is more than 10 times the upper limit of normal.

The best means of detecting myopathy clinically is physician's awareness of the main risk factors, in particular understanding the potential for drug interactions, which are product-specific. One should also have a high index of suspicion when high doses of statin are being used.

\section{Management of Myopathy}

If myopathy or rhabdomyolysis is detected, statin therapy should be immediately stopped. If creatine kinase is substantially raised (e.g. $>10000 \mathrm{IU} / \mathrm{L}$ ), a high fluid intake is advised to minimise the risk of renal impairment. Full recovery usually occurs within few weeks. If particular drug interaction has been implicated, the culprit drug should be withdrawn. After creatine kinase has come down to normal level, one can restart the same statin at low dose or an alternative statin can be tried with careful monitoring. Although, most cases of myopathy occur within first months of initiation of therapy, muscle involvement can occur after some years of apparently stable statin treatment, usually as a result of starting an interacting drug.

\section{Effects of Statins on Liver}

Drugs in general are an important cause of liver disease and drug-induced hepatotoxicity may mimic almost any type of hepatobiliary disease from fulminant hepatic failure to chronic liver disease with cirrhosis. Despite case reports of liver disease in persons taking statins, evidence indicates that liver disease attributable to statins is rare. ${ }^{18}$ Typically with standard doses, little or no effect is seen on gamma glutamyl transferase, alkaline phosphatase and bilirubin. ${ }^{19}$, though a small percentage of patients experience an increase in liver enzymes like alanine and aspartate transaminase. 1 The increases in transaminase are seen within first six months of therapy with statins. Elevations of these enzymes produce no symptoms and reverse on stopping the drug or with dose reduction.

It is debatable whether the effect on transaminases indicates hepatotoxicity or rather some sort of hepatic reaction to reduction of lipid levels. Other cholesterollowering agents including resins, niacin and ezetimibe also increase the liver enzymes. This suggests that these changes could be a hepatic response to lipid-lowering than hepatotoxity. 20

\section{Standard Doses and Effects on Liver}

Data from randomized trials do not indicate that statins are hepatotoxic. ${ }^{5}$ Although hepatitis and liver failure have been reported spontaneously and from trials of statins, it is not clear whether they are causally related or that the risk is over and above the background risk of sporadic liver failure. Only a small number of patients demonstrate elevation of transaminase levels in the first few months of statin therapy. In the Heart Protection Study, there was no significant excess of patients overall with elevated liver enzymes (Alanine transaminase more than three times the upper limit of normal, $77[0.75 \%]$ simvastatin vs 63 [0.63\%] placebo, $p=0.36) .{ }^{17}$ However, there were more confirmed increases of alanine transaminase in the first 4 months of study $(8,0.08 \%$ simvastatin vs $0.00 \%$ placebo) compared with later in the trial. 


\section{Higher Doses and Effects on Liver}

The effect of statins on transaminases seems to be dependent on statin dose, and effects on other liver enzymes and bilirubin emerged with higher doses.21 But, unlike with myopathy, the effects might be because of a greater fall in LDL cholesterol. In the large atorvastatin database, less than $0.2 \%$ of patients on placebo or atorvastatin $10 \mathrm{mg} /$ day had persistent raised alanine or aspartate transaminase compared with $0.6 \%$ of those on atorvastatin $80 \mathrm{mg} /$ day. ${ }^{21}$ The long-term large randomized trials of atorvastatin $80 \mathrm{mg} /$ day compared with lower statin dose or placebo demonstrate the excess of persistent elevations of transaminases with this dose of atorvastatin (Table 2). However, no trial has reported any hepatitis or hepatic failure. ${ }^{10,11,13}$

\section{Management of Elevated Transaminases}

The lack of effect of statins on adverse hepatic outcomes (with the possible exception of atorvastatin $80 \mathrm{mg} /$ day) is reassuring to the physicians. Statin product information recommends baseline measurements of liver function and advocates against the use of the drugs in presence of active liver disease. At standard doses, effects on liver enzymes are rare $(<1 \%)$, but at higher doses different statins vary in degree to which they raise the liver enzymes. ${ }^{5}$ Hence, a logical approach is to increase the statin dose slowly in those at risk of transaminase elevations. Routine monitoring of liver enzymes after starting statins is no longer recommended for simvastatin, pravastatin or lovastatin up to $40 \mathrm{mg}$ daily. However, monitoring of these enzymes is necessary for higher doses of the statins and also for other statins.

If alanine or aspartate transaminases are more than three times the upper limits of normal in asymptomatic patients without any other liver abnormalities, the enzymes should be rechecked within a week and statins should be stopped temporarily if the enzymes are still elevated. Increases to between two to three times the upper limit of normal in an asymptomatic patient necessitate frequent monitoring, but will often resolve while on treatment.

Most of the randomized trials have excluded patients with levels more than 1.2, 1.5 or 2 times the upper limit of normal, and so the safety of statins in these people has not been systematically assessed. Further, non-alcoholic steatohepatitis (Fatty liver) may actually improve with lipid lowering therapy.22,23 If, however, other liver function tests such as serum bilirubin are abnormal or the enzymes are suggestive of an obstructive picture, it is prudent to avoid statins.

\section{Statins and Neurologic Diseases \\ Haemorrhagic Stroke}

The randomized clinical trials of serum cholesterol reduction has not shown any increase in haemorrhagic stroke in treated patients. Importantly, however, the number of haemorrhagic strokes recorded in the trial was rather small: 149 haemorrhagic strokes compared with 1,284 thromboembolic strokes and 1966 strokes of undetermined subtype. Accordingly, the $95 \% \mathrm{CI}$ on the risk estimate for haemorrhagic stroke was rather wide from a $35 \%$ reduction to a $47 \%$ increase for a $1 \mathrm{mmol} / \mathrm{L}$ increase in LDL cholesterol. ${ }^{15}$

An analysis of 9 cohort studies of serum cholesterol and stroke has shown that lower LDL cholesterol level is associated with a higher risk of haemorrhagic stroke. ${ }^{15}$ However, the evidence is insufficient to attribute it to cause and effect and no mechanism is apparent. This uncertainty need not affect the use of statins to prevent cerebrovascular disease, because the possible excess of haemorrhagic stroke is greatly outweighed by the protective effect against thromboembolic stroke. However, patients who have already had a haemorrhagic stroke should not be given a cholesterol lowering drug. ${ }^{8}$

\section{Cognitive Function}

Some case reports have suggested that statins accelerate impairment in cognitive function. ${ }^{8}$ Cognitive status was measured in the Heart Protection Study (HPS) after 5 years of taking simvastatin $(n=10,269)$ or placebo $(n=10,207) .{ }^{24}$ Cognitive impairment was detected in similar proportions of participants allocated simvastatin (23.7\%) and placebo $(24.2 \%)$ as was dementia $(0.3 \%)$. These observations in large numbers of participants establish beyond doubt that statins cause no perceptible decline in cognitive function.

\section{Peripheral Neuropathy}

In the largest of the studies suggesting that statins may cause peripheral neuropathy, a relative risk of 3.7 (95\%; CI 1.8 - 7.6) was reported in association with 2-3 years low dose statin therapy. ${ }^{25}$ But in the Heart Protection Study, the absolute risk of peripheral neuropathy was very low $(11,0.1 \%$; simvastatin vs $8,0.1 \%$ placebo) with no significant excess in those allocated simvastatin over 5 years. ${ }^{24}$ This minor hazard is no reason to limit the use of statins, except that they should be discontinued if peripheral neuropathy develops. ${ }^{25}$

\begin{tabular}{|c|c|c|c|c|c|c|}
\hline & $\begin{array}{c}\text { Statin } \\
\text { Comparison } \\
\text { Higher vs } \\
\text { Lower }\end{array}$ & $\begin{array}{c}\text { Medical } \\
\text { Condition of } \\
\text { Participants }\end{array}$ & \begin{tabular}{|c|} 
Alanine \\
Transaminase 3 \\
Times Upper limit \\
of Normal Higher vs \\
Lower
\end{tabular} & $\begin{array}{l}\text { Creatine Kinase } \\
10 \text { times upper } \\
\text { Limit of Normal, } \\
\text { or Myopathy } \\
\text { Higher vs Lower }\end{array}$ & $\begin{array}{l}\text { Rhabdomyolysis } \\
\text { Higher vs Lower }\end{array}$ & $\begin{array}{l}\text { Non- } \\
\text { Vascular } \\
\text { Death } \\
\text { Higher vs. } \\
\text { Lower }\end{array}$ \\
\hline $\begin{array}{c}\text { PROVE-IT } \\
(4162)\end{array}$ & $\begin{array}{c}\text { A } 80 \mathrm{mg} \text { vs } \mathrm{P} \\
40 \mathrm{mg}\end{array}$ & $\begin{array}{r}\text { Acut } \\
\text { sy } \\
\end{array}$ & $\begin{array}{c}69(3.3 \%) \text { vs } 23 \\
(1.1 \%)\end{array}$ & $\begin{array}{c}2(0.1 \%) \text { vs } \\
3(0.15 \%)\end{array}$ & $0(0 \%)$ vs $0(0 \%)$ & $\begin{array}{c}17(0.8 \%) \text { vs } \\
27(1.3 \%) \\
\end{array}$ \\
\hline $\begin{array}{c}\text { Phase } \mathrm{Z} \text { of the } \\
\text { A to } \mathrm{Z} \text { trial } \\
(4497)\end{array}$ & $\begin{array}{c}\mathrm{S} 80 \mathrm{mg} \text { vs S } 20 \\
\mathrm{mg}\end{array}$ & $\begin{array}{l}\text { Acute coronary } \\
\text { syndromes }\end{array}$ & $19(0.9 \%)$ vs $8(0.4 \%)$ & $\begin{array}{c}9(0.4 \%) \text { vs } \\
1(0.04 \%)\end{array}$ & $3(0.1 \%)$ vs $0(0 \%)$ & $\begin{array}{c}21(0.9 \%) \text { vs } \\
21(0.9 \%)\end{array}$ \\
\hline TNT (10001) & $\begin{array}{c}\text { A } 80 \mathrm{mg} \text { vs A } \\
10 \mathrm{mg}\end{array}$ & Stable CHD & $60(1.2 \%)$ vs $9(0.2 \%)$ & $(0.0 \%)$ vs $(0.0 \%)$ & $\begin{array}{c}2(0.04 \%) \text { vs } \\
3(0.06 \%)\end{array}$ & $\begin{array}{c}158(3.2 \%) \text { vs } \\
127(2.5 \%) \\
\end{array}$ \\
\hline IDEAL (8888) & $\begin{array}{l}\text { A } 80 \mathrm{mg} \text { vs S } \\
20-40 \mathrm{mg}\end{array}$ & Stable CHD & $\begin{array}{c}43(0.97 \%) \text { vs } \\
5(0.11 \%)\end{array}$ & $\begin{array}{c}6(0.14 \%) \text { vs } \\
11(0.25 \%)\end{array}$ & $\begin{array}{c}2(0.05 \%) \text { vs } \\
3(0.07 \%)\end{array}$ & $\begin{array}{c}143(3.2 \%) \text { vs } \\
156(3.5 \%)\end{array}$ \\
\hline $\begin{array}{l}\text { SPARCL } \\
(4731) \\
\end{array}$ & $\begin{array}{c}\text { A } 80 \mathrm{mg} \text { vs } \\
\text { placebo }\end{array}$ & $\begin{array}{c}\text { Post stroke or } \\
\text { TIA (no CHD\%) } \\
\end{array}$ & $\begin{array}{c}51(2.2 \%) \text { vs } \\
11(0.5 \%)\end{array}$ & $7(0.3 \%)$ vs $(0.3 \%)$ & $2(0.1 \%)$ vs $3(0.1 \%)$ & $\begin{array}{c}117(4.9 \%) \text { vs } \\
94(3.9 \%)\end{array}$ \\
\hline
\end{tabular}


CHD: Coronary Heart Disease; TIA: Transient Ischaemic Attack; A: Atorvastatin, P: Pravastatin; S: Simvastatin

\section{Statins and Kidney Diseases}

Rosuvastatin has been associated with an increase in the risk of proteinuria, particularly at higher doses. ${ }^{26}$ It is usually transient and has not been associated with worsened renal function. Combined data from 3 trials of pravastatin showed that renal failure or other renal disease designating a serious adverse event occurred in $48(0.5 \%)$ participants allocated pravastatin and $78(0.8 \%)$ allocated placebo. ${ }^{27}$ None of the randomized trials has reported proteinuria or renal disease occurring significantly more frequently in patients allocated statins than in participants given placebo. ${ }^{8}$ Thus, there is no indication that statin at current market dose causes renal disease.

\section{Safety of Statins in Specific Subgroups Pregnancy}

Statins are contraindicated in pregnancy and breast feeding. Premenopausal women treated with statins should be warned to avoid becoming pregnant and to stop treatment if they plan to conceive, because there are reports of congenital abnormalities in the babies of women who took statins during early pregnancy. 28

\section{Elderly Patients}

No dose adjustment is necessary for elderly patients put on statins, although the very elderly may be at increased risk of myopathy. People up to the age of 80 years have been included in the randomized trials, and the safety profile and relative benefits of the treatment are generally similar to those in the younger adults. 2,17

\section{Children}

Statin therapy is rarely indicated for children with severe familial hypercholesterolemia and should always be prescribed under specialist care. Long-term effects of treating children with statin are unknown, but short-term and small scale studies in children and adolescents have not raised safety concerns and no adverse effects have been seen on growth or sexual maturation. 29

\section{Alcohol Consumption \\ Most large randomized trials excluded people with excessive alcohol consumption from participation making assessment of the safety of statins in these people difficult. In the Heart Protection Study, no upper limit for alcohol intake was imposed provided that liver function tests were within acceptable ranges and patients were thought likely to be compliant.30 Over 2000 (11\%) reported baseline alcohol intake $>21$ units/week and there was no evidence that these people were at any greater risk of myopathy or of statin- associated excess of raised transaminases.}

\section{CONCLUSIONS}

Statins, a well-tolerated and extensively studied group of drugs are safe when used at their usual doses. The recognised adverse effects, most importantly myopathy and rhabdomyolysis are rare and as with most drugs increase with higher doses. Myopathy attributable to statins is extremely rare (11 per 100,000 person years). Incidence of rhabdomyolysis is still lower in patients taking atorvastatin, simvastatin, lovastatin or pravastatin (3 per 100,000 person years). Most muscle symptoms in patients taking statins are not attributable to statins. Measurement of creatine kinase in such patients can exclude myopathy and allow safe continuation of the treatment. Drugs that inhibit CYP3A4 are taken by about $60 \%$ of patients using atorvastatin, simvastatin or lovastatin who develop rhabdomyolysis, thus reducing the dose in these circumstances would be expected to prevent many cases. Co-prescription of a statin with gemfibrozil is also a preventable cause of rhabdomyolysis.

Mounting evidence indicates that liver disease attributable to statin is rather rare. Data from randomized trials do not indicate that statins are hepatotoxic. Given the proven benefits of statins, labelling people as statin-intolerant because of effects on liver enzymes has potentially important consequences for their cardiovascular risk management, so needs to be done carefully. Similarly, there is no evidence that statins cause renal disease or cognitive decline.

\section{REFERENCES}

1. Grundy SM. HMG-Co a reductase inhibitors for treatment of hypercholesterolemia. N Engl J Med 1988;319(1):2433.

2. Baigent C, Keech A, Kearney PM, et al. Efficacy and safety of cholesterol-lowering treatment: prospective metaanalysis of data from 90,056 participants in 14 randomised trials of statins. Lancet 2005;366(9493):1267-78.

3. Pasternak RC, Smith SC, Bairey-Merz CN, et al. ACC/AHA/NHLBI clinical advisory on the use and safety of statins. Stroke 2002;33(9):2337-41.

4. Shitara Y, Sugiyama Y. Pharmacokinetic and pharmacodynamic alterations of 3-hydroxy-3methylglutaryl coenzyme a (HMG-CoA) reductase inhibitors: drug-drug interactions and inter-individual differences in transporter and metabolic enzyme functions. Pharmacol Ther 2006;112(1):71-105.

5. Armitage J. The safety of statins in clinical practice. Lancet 2007;370(9601):1781-90.

6. Davidson MH, Clark JA, Glass LM, et al. Statin safety: an appraisal from the adverse event reporting system. Am J Cardiol 2006;97(8A):32C-43.

7. McKenney JM, Davidson MH, Jacobson TA, et al. Final conclusions and recommendations of the national lipid association statin safety assessment task force. Am J Cardiol 2006;97(8A):89C-94.

8. Law M, Rudnicka AR. Statin safety: a systematic review. Am J Cardiol 2006;97(8A):52C-60.

9. Matsuzawa $\mathrm{Y}$, Kita $\mathrm{T}$, Mabuchi $\mathrm{H}$, et al. Sustained reduction of serum cholesterol in low-dose 6 year simvastatin treatment with minimum side effects in 51, 321 Japanese hypercholesterolemic patients. Circ J 2003; 67:287-294.

10. LaRosa JC, Grundy SM, Waters DD, et al. Intensive lipid lowering with atorvastatin in patients with stable coronary disease. N Engl J Med 2005;352:1425-35.

11. Pedersen TR, Faergeman 0, Kastelein JJP, et al. High-dose atorvastatin vs usual-dose simvastatin for secondary prevention after myocardial infarction: the IDEAL study a randomized controlled trial. JAMA 2005;294 (19):2437-45. 
12. Cannon $\mathrm{CP}$, Braunwald $\mathrm{E}$, McCabe $\mathrm{CH}$, et al. Intensive versus moderate lipid lowering with statins after acute coronary syndromes. N Engl J Med 2004;350:1495-504.

13. The stroke prevention by aggressive reduction in cholesterol levels (SPARCL) investigators. High-dose atorvastatin after stroke or transient ischaemic attack. N Engl J Med 2006;355:549-559.

14. Chang JT, Stafa JA, Parks M, et al. Rhabdomyolysis with HMG-CoA reductase inhibitors and gemfibrozil combination therapy. Pharmaco Drug Saf 2004;13(7):417-26.

15. Law MR, Wald NJ, Rudnicka AR. Quantifying effect of statins on low density lipoprotein cholesterol, ischaemic heart disease and stroke: systematic review and metaanalysis. BMJ 2003;326:1423-30.

16. Prueksaritanont T, Zhao JJ, Ma B, et al. Mechanistic studies on metabolic interactions between gemfibrozil and statins. Pharmacol Exp Ther 2002;301(3):1042-51.

17. Heart protection study collaborative group. MRC/BHF heart protection study of cholesterol lowering with simvastatin in 20536 high-risk individuals: a randomised placebo-controlled trial. Lancet 2002;360(9326):7-22.

18. Kinnman N, Hultcrantz. Lipid lowering medication and hepatotoxicity. Intern Med 2001;250(3):183-5.

19. Keech A, Collins R, MacMahon S, et al. Three-year followup of the oxford cholesterol study: assessment of the efficacy and safety of simvastatin in preparation for a large mortality study. Eur Heart J 1994;15(2):255-69.

20. Tolman KG. The liver and lovastatin. Am J Cardiol 2002;89(12):1374-80.

21. Ballantyne CM, Blazing MA, Hunnighake B, et al. Effect on high- density lipoprotein cholesterol of maximum dose simvastatin and atorvastatin in patients with hypercholesterolemia: results of the comparative HDL efficacy and safety study (CHESS). Am Heart J 2003;146(5):862-9.
22. Newman C, Tasi J, Szarek M, et al. Comparative safety of atorvastatin $80 \mathrm{mg}$ versus $10 \mathrm{mg}$ derived from analysis of 49 completed trials in 14236 patients. Am J Cardiol 2006;97(1):61-7.

23. Angulo P. Non-alcoholic fatty liver disease. N Engl J Med 2002;346:1221-31.

24. Collins R, Armitage J, Parish S, et al. Effects of cholesterol lowering with simvastatin on stroke and other major vascular events in 20,536 people with cerebrovascular disease or other high risk conditions. Lancet 2004;363(9411):757-67.

25. Gaist D, Jeppesen $U$, Andersan M, et al. Statins and risk of polyneuropathy a case control study. Neurology 2002;58:1333-7.

26. Vidt DG, Cressman MD, Havri S, et al. Rosuvastatin induced arrest in progression of renal disease. Cardiology 2004;102(1):52-60.

27. Pfeffer MA, Keech A, Sacks FM, et al. Safety and tolerability of pravastatin in long-term clinical trials. Circulation 2002;105(20):2341-6.

28. Edison RJ, Muenke M. Central nervous system and limb anomalies in case reports of first trimester statin exposure. N Engl J Med 2004;350:1579-82.

29. McCrindle BW, Ose I, Marias AD. Efficacy and safety of atorvastatin in children and adolescents with familial hypercholesterolemia or severe hyperlipidaemia a multicentre and randomized, placebo- controlled trial. J Paediatr 2003;143(1):74-80.

30. Collins R, Armitage J, Parish S, et al. Heart protection study of cholesterol-lowering with simvastatin in 5963 people with diabetes: a randomised placebo-controlled trial. Lancet 2003;361(9374):2005-16. 